\title{
Prediction of the hypertension risk in teenagers
}

\author{
Piotr Wieniawski, Bożena Werner
}

Department of Pediatric Cardiology and General Pediatrics, Medical University of Warsaw, Poland

\begin{abstract}
Background: Creation of a hypertension risk stratification model and development of an algorithm to detect hypertension in teenagers.

Methods: The study group consisted of 690 middle and high school students, aged 15-17 years, from the metropolitan area of Warsaw, Poland. Information concerning family history and presence of risk factors for cardiovascular disease was gathered. Three-time blood pressure measurements were taken during at least two separate visits, which were at least a week apart, using the auscultatory method, according to standard procedures. Anthropometric measurements included: body weight, height, arm, hip and abdominal circumference, skin-fold thickness measured on the rear surface of an arm, below the inferior angle of the scapula and at the belly. Following indexes were determined: body mass index, waist to hip ratio (WHR), waist to height ratio, hip to height ratio.

Results: A logistic regression model, describing the risk of hypertension in adolescents aged 15-17 was invented. $\hat{\pi}(\mathrm{x})=\frac{\mathrm{e}^{g(x)}}{1+e^{(s)}}$ where $\hat{\mathrm{g}}(x)=-0.097 \times$ height $+0.085 \times$ weight $+7.764 \times W H R+1.312 \times$ $\times$ family hypertension. Family hypertension means presence of hypertension among members of the closest family. The formula was created, allowing the pre-selection of adolescents at risk of hypertension during screening. Next an algorithm for the detection of hypertension for practical use was proposed.

Conclusions: Body weight, WHR and incidence of hypertension in the family are the strongest predictors of hypertension in teenagers. Proposed screening algorithm can be a useful tool for selecting teenagers at risk of hypertension and in need of specialized diagnostics and care. (Cardiol J 2022; 29, 6: 994-1003)
\end{abstract}

Key words: primary hypertension, hypertension risk stratification, hypertension in children, hypertension in teenagers, prediction of hypertension

\section{Introduction}

Hypertension is not an isolated phenomenon in pediatric populations and needs to be treated in the same way as other diseases of a chronic nature. The strategy of prevention and treatment in the light of available research should be long-term and focused on reducing the number of complications in adulthood.

Hypertension affects $20-30 \%$ of the global population and in most cases its form is essential hypertension [1-9]. Polish multicenter population based studies showed that hypertension affects about $30-35 \%$ of adult Poles and the incidence of hypertension increases with age [10-13]. The number of adolescents with essential hypertension has rapidly increased in number. According to some authors, in older age groups the problem of hypertension may affect eight or even over a dozen percent of adolescents [8, 14-17].

The incidence of hypertension in the population under 18 years of age is estimated at $2-5 \%$. More recent epidemiological studies have revealed a marked increase in the percentage of children with primary hypertension. It is estimated that it affects $4 \%$ of the pediatric population and increases with age and that the percentage of children with high normal blood pressure (BP) valuesare more than twice as high (9\%). The results of the OLAF study carried out in Poland from 2007 to 2009 with the participation of over 17,000 students aged 6.5-18.5 years, were similar to those in previous studies and showed the incidence of hypertension in the studied age group to range between $3 \%$ and

Address for correspondence: Prof. Bożena Werner, MD, PhD, Head of Department of Pediatric Cardiology and General Pediatrics, Medical University of Warsaw, ul. Żwirki i Wigury 63A, 02-091 Warszawa, Poland, e-mail: bozena.werner@wum.edu.pl 
$3.5 \%[18,19]$. Essential hypertension is the predominant form of hypertension in children older than 10 years of age [20,21].

In all developed and developing countries there is a tendency for diagnosing essential hypertension in younger and younger children, which goes hand in hand with the observed parallel increase in the prevalence of overweight and obesity in the pediatric age [22-26].

It is estimated that in Europe, 1 in 5 children is overweight or obese, and approximately 400,000 new cases of overweight and obesity are annually recognized among children and adolescents [27, 28].

With increasing rates of obesity in children and adolescents, the proportion of primary hypertension increases and it is diagnosed in about $50 \%$ of all children evaluated due to hypertension [18]. Fortunately, in recent years the percentage of obese children in developed countries has been reported to be in a plateau phase or even decreasing in number. According to recent studies, $11-12.5-14.8 \%$ of Polish teenagers are overweight and obese. Several other large population analyzes, that had been carried out in Poland in the last few years - depending on the methodology used - have revealed that $8-10.5-14.2 \%$ of boys are overweight and 7-6.8-6.4\% of boys are obese. In girls, respectively - overweight is observed in $10.5-12-13 \%$; obesity in 11-10-7.7\%. Excess body weight is significantly higher in girls than boys and in children living in the cities rather than in those in countryside [29-33].

Even in the developmental age significant damage of the arteries and left ventricular hypertrophy are observed. Overall, left ventricular hypertrophy and thickening of the intima-media complex of carotid arteries are observed in even up to $40 \%$ of children at the time of diagnosis of essential hypertension, before the introduction of any antihypertensive treatment [8, 16, 20, 34-37].

The aim of the present study was the creation of a hypertension risk stratification model and development of an algorithm to detect hypertension in teenagers.

The idea behind this study was to create a simple questionnaire - based on the developed risk model - which would be accessible for each student by a dedicated website, e-mail or a smartphone application. To complete questionaire students would neither have to know or measure their BP values.

The goal was to develop an algorithm that would inform students of what the likelihood of abnormal test result means, what the potential complications are as well as to suggest further steps.

\section{Methods}

In this prospective study 690 middle school and high school students aged $15-17$ years who underwent screening were enrolled. Schools were chosen at random. They were larger and smaller high schools in Warsaw and smaller cities. The tests were also conducted in two small village schools. There were sports classes in some of those schools. No student in the studied group had been diagnosed or suspected of having hypertension before.

Information concerning family history and the presence of risk factors for cardiovascular disease was gathered based on the questionnaire.

Blood pressure measurements were taken using the auscultatory Korotkoff method with the aid of a manual aneroid sphyngomanometer, according to standards contained in The Fourth Report on the Diagnosis, Evaluation and Treatment of High Blood Pressure in Children and Adolescents (4 TFBP) and Guidelines of the Pediatric Section of the Polish Society of Hypertension on diagnosis and treatment of arterial hypertension in children and adolescents [18, 36, 38]. Blood pressure measurements were taken 3 times during at least 2 separate visits, at least a week apart and the values were related to values contained in the 4 TFBP $[36,38]$. In accordance with current recommendations, the criteria for diagnosing hypertension in students over 16 years of age were the same as those used in adult populations [18].

In all patients admitted to the Department of Cardiology, automatic BP measurements were performed using the oscillometric method. The results of the BP measurement using the oscillometric method were referred to standards developed during the OLAF study [19]. In all students with suspected hypertension, 24-hour arterial blood pressure monitoring (ABPM) was performed. Blood pressure values obtained by ABPM were assessed on the basis of centile charts recommended by the American Heart Association (AHA) adapted from Wühl and the team, with permission from Lippincott Williams \& Wilkins [39, 40]. Arterial hypertension was diagnosed when systolic $\mathrm{BP}$ and/or diastolic $\mathrm{BP} \geq 95^{\text {th }}$ percentile according to norms for sex, age and/or height were found. Students who were diagnosed with arterial hypertension on the basis of a screening test prior to being reported to the cardiology department 
Table 1. Basic statistics of the study group including parameters used in the algorithm and of the control group on which the model was tested.

\begin{tabular}{|c|c|c|}
\hline & $\begin{array}{c}\text { Study group for which the algorithm } \\
\text { was created, } n=690 \\
366 \text { boys }(53 \%) ; 324 \text { girls }(47 \%)\end{array}$ & $\begin{array}{c}\text { Control group, } n=108 \\
50 \text { boys }(46.3 \%) ; 58 \text { girls }(53.7 \%)\end{array}$ \\
\hline Age [years] & $\begin{array}{c}15.65 \pm 0.86 \\
\text { min. } 14 ; \text { max. } 17 ; \text { median } 15.0\end{array}$ & $\begin{array}{c}15.7 \pm 0.77 \\
\text { min. } 14 ; \text { max. } 17 ; \text { median } 16.0\end{array}$ \\
\hline Weight [kg] & $\begin{array}{c}61.5 \pm 12.4 ; \\
\min .37 .5 ; \max .119 ; \text { median } 59.5\end{array}$ & $\begin{array}{c}62.5 \pm 14.4 ; \\
\min .38 ; \text { max. } 101 ; \text { median } 59.7\end{array}$ \\
\hline Hight $[\mathrm{cm}]$ & $\begin{array}{c}169 \pm 8.3 ; \\
\text { min. 148; max. 191.5; median } 169\end{array}$ & $\begin{array}{c}167 \pm 9.0 ; \\
\text { min. } 140.5 ; \text { max. } 189 ; \text { median } 166\end{array}$ \\
\hline Waist circumference & $\begin{array}{c}72.6 \pm 9.0 ; \\
\text { min. } 52 ; \text { max. } 117 ; \text { median } 71\end{array}$ & $\begin{array}{c}76.4 \pm 10.9 \\
\text { min. } 61 ; \max .110 ; \text { median } 74.5\end{array}$ \\
\hline Hip circumference & $\begin{array}{c}83.5 \pm 8.6 \\
\text { min. } 63 ; \text { max. } 120 ; \text { median } 82\end{array}$ & $\begin{array}{c}95.6 \pm 8.7 ; \\
\text { min. } 74 ; \text { max. } 123 ; \text { median } 95\end{array}$ \\
\hline Waist to hip ratio & $\begin{array}{c}0.87 \pm 0.06 ; \\
\text { min. } 0.62 ; \text { max. } 1.08 ; \text { median } 0.87\end{array}$ & $\begin{array}{c}0.8 \pm 0.08 ; \\
\min .0 .6 ; \max .1 .07 ; \text { median } 0.79\end{array}$ \\
\hline $\mathrm{SBP}[\mathrm{mmHg}]$ & $\begin{array}{c}112.3 \pm 12.2 \\
\min .82 .0 ; \text { max. } 158 ; \text { median } 112.7\end{array}$ & $\begin{array}{c}118.5 \pm 12.2 ; \\
\min .97 .5 ; \text { max. } 145 ; \text { median } 117.2\end{array}$ \\
\hline $\mathrm{DBP}[\mathrm{mmHg}]$ & $\begin{array}{c}66.9 \pm 6.9 ; \\
\min .50 .5 ; \max .101 .0 ; \text { median } 66.0\end{array}$ & $\begin{array}{c}68.7 \pm 9.2 ; \\
\min .50 .0 ; \text { max. } 100.0 ; \text { median } 68.0\end{array}$ \\
\hline Hypertension & $\mathrm{N}=40(5.8 \%)$ & $\mathrm{N}=11(10.2 \%)$ \\
\hline \multirow[t]{2}{*}{ Family hypertension } & $\begin{array}{c}\mathrm{N}=479(69 \%) \text { at least one close family } \\
\text { member with hypertension }\end{array}$ & $\begin{array}{c}\mathrm{N}=51(47 \%) \text { at least one close family } \\
\text { member with hypertension }\end{array}$ \\
\hline & $\begin{array}{c}\mathrm{N}=163(23.6 \%) \text { more than one person } \\
\text { in closest family with hypertension }\end{array}$ & $\begin{array}{l}\mathrm{N}=26(24 \%) \text { more than one person } \\
\text { in closest family with hypertension }\end{array}$ \\
\hline
\end{tabular}

SBP — mean systolic blood pressure; DBP — mean diastolic blood pressure

for further diagnosis were advised to perform $\mathrm{BP}$ measurements at home.

Anthropometric measurements included: body weight, height, arm, hip and abdominal circumference. Skin-fold thickness was measured on the rear surface of the freely lowered arm, on the back below the inferior angle of the scapula, at the belly - midway between the umbilicus and the anterior superior iliac spine, and one third of the distance between the anterior superior iliac spine and the pubic symphysis.

On the basis of measurements taken, the following indexes were determined: body mass index (BMI), waist to hip ratio (WHR), waist to height ratio (WHtR), hip to height ratio - body adiposity index [36, 38, 41-43].

For analysis the following statistical methods were used: the Shapiro-Wilk test, the t-Student test, the U Mann-Whitney test (the Wilcoxon Rank Sum Test), the non-parametric $\chi^{2}$ test, the Pearson correlation coefficient, the Kruskal-Wallis test in analysis of variance (ANOVA).

All hypotheses were tested with a significance level 0.05. Logistic regression analysis was conducted in order to assess probability of hypertension occurrence. Variables that could have influenced the risk of hypertension in children were searched for. The algorithm was tested for: sensitivity, specificity, positive predictive value, negative predictive value in the tested group and receiver operating characteristic (ROC) analysis was performed. For statistical analysis $\mathrm{R}$ software version 3.1 was used.

The study was approved by the University Bioethics Committee. Approval number of the Bioethics Committee KB/204/2009. The study was carried out according to the World Medical Association Declaration of Helsinki.

\section{Results}

In the present study 690 students aged $15-17$ years were enrolled, 366 boys and 324 girls. Hypertension was diagnosed in $40(5.8 \%)$ adolescents: $22(3.2 \%)$ boys and $18(2.6 \%)$ girls. Basic statistics of the study group including parameters used in the algorithm are listed in Table 1.

Afterwards the influence of selected factors on the prevalence of hypertension was evaluated. Statistically significant differences in mean values 


\begin{tabular}{|c|c|c|c|c|c|c|c|c|c|c|c|c|c|c|c|c|}
\hline & 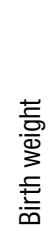 & 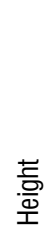 & 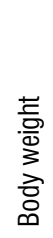 & $\sum_{\infty}$ & 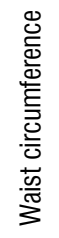 & 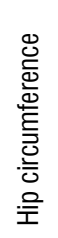 & 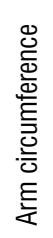 & 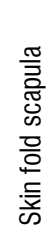 & 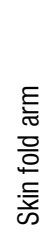 & $\begin{array}{l}\overline{ } \\
\overline{\overline{0}} \\
\text { 음 } \\
\frac{0}{0} \\
\frac{\bar{x}}{0}\end{array}$ & $\begin{array}{l}\text { N } \\
\stackrel{\bar{d}}{\bar{\Delta}} \\
\frac{0}{0} \\
\frac{0}{0} \\
\frac{\bar{x}}{D}\end{array}$ & 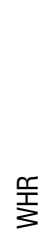 & 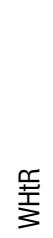 & 吕 & 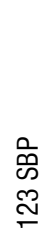 & 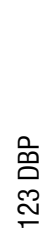 \\
\hline Birth wei & & & & & & & & & & & & & & & & \\
\hline Height & & & & & & & & & & & & & & & & \\
\hline Body wei & & & & & & & & & & & & & & & & \\
\hline BMI & & & & & & & & & & & & & & & & \\
\hline Waist circ & & & & & & & & & & & & & & & & \\
\hline Hip circu & & & & & & & & & & & & & & & & \\
\hline Arm circl & & & & & & & & & & & & & & & & \\
\hline Skin fold & & & & & & & & & & & & & & & & \\
\hline Skin fold & & & & & & & & & & & & & & & & \\
\hline Skin fold & & & & & & & & & & & & & & & & \\
\hline Skin fold & & & & & & & & & & & & & & & & \\
\hline WHR & & & & & & & & & & & & & & & & \\
\hline WHtR & & & & & & & & & & & & & & & & \\
\hline BAl & & & & & & & & & & & & & & & & \\
\hline 123 SBP & & & & & & & & & & & & & & & & \\
\hline $123 \mathrm{DBP}$ & & & & & & & & & & & & & & & & \\
\hline
\end{tabular}

Figure 1. Correlation between analyzed parameters in the study group. Maroon - correlation power $\geq 0.9$; $<0.00001$; Red - correlation power $\geq 0.8 ; p<0.00001$; Orange - correlation power $\geq 0.75 ; p<0.00001$; Yellow — correlation power $\geq 0.6 ; \mathrm{p}<0.00001$; Light yellow - correlation power $\geq 0.3 ; \mathrm{p}<0.001$; SBP — systolic blood pressure; DBP — diastolic blood pressure; BMI — body mass index; WHR — waist to hip ratio; WHtR - waist to height ratio; $\mathrm{BAl}$ - body adiposity index (hip to height ratio); skin fold scapula - skin-fold thickness on the back below the inferior angle of the scapula; skin fold arm — skin-fold thickness on rear surface of freely lowered arm; skin fold belly 1 - skin-fold thickness at the belly midway between the umbilicus and the anterior superior iliac spine; skin fold belly 2 - skin-fold thickness at the belly in third of the distance between the anterior superior iliac spine and the pubic symphysis.

( $\mathrm{p}<0.001)$ of both systolic and diastolic BP values were observed, depending on weight category, as defined by BMI. The highest mean values of systolic and diastolic BP occurred in adolescents with obesity, was slightly lower among adolescents who were overweight, and was lowest in adolescents with normal body weight and body mass deficiency $(p<0.001)$. It was estimated that the risk of hypertension for an obese adolescent is over 13 times greater than that of an adolescent who is not obese.

Hypertension was more frequent $(p=0.004)$ in adolescents who had at least one parent who suffered from hypertension. Hypertension was diagnosed in $22(10.8 \%)$ of 204 adolescents who had at least one parent with diagnosed hypertension. Among a group over twice as large, consisting of 464 adolescents whose parents did not suffer from hypertension, there were only 18 adolescents with diagnosed hypertension, representing 3.9\%. What is more, among the 447 adolescents who had at least one person among their next of kin who suffered from high BP, hypertension was diagnosed in 32 (6.9\%), and among the 243 adolescents who did not have anyone in their family suffering from hypertension - only $5(2.1 \%)$ met the criteria for diagnosis of hypertension $(\mathrm{p}=0.030)$. It has been estimated that the risk of hypertension for a pupil from a family where at least one person suffers or had suffered from hypertension, is more than 2.8 times higher than that of an adolescent, who had no history of family hypertension (Fig. 1).

A logistic regression model describing the probability of hypertension in adolescents was used to verify which of the analyzed parameters 
Table 2. Results of the logistic regression model describing the probability of hypertension in adolescents.

\begin{tabular}{lccccc}
\hline & CE & $95 \%$ CE & OR & $95 \%$ CI OR & P \\
\hline Body height & -0.097 & $(-0.13 ;-0.066)$ & 0.91 & $(0.88 ; 0.93)$ & $<0.0001$ \\
Weight & 0.085 & $(0.06 ; 0.11)$ & 1.09 & $(1.06 ; 1.12)$ & $<0.0001$ \\
WHR & 7.764 & $(2.16 ; 13.55)$ & 2355 & $(8.66 ; 762608)$ & 0.007 \\
Family hypertension & 1.312 & $(0.35 ; 2.5)$ & 3.7 & $(1.41 ; 12.2)$ & 0.015 \\
\hline
\end{tabular}

Family hypertension ( 1 if hypertension in 1 of the family members, 2 if hypertension in 2 of the family members etc.); CE - coefficient-estimate; WHR - waist to hip ratio; OR - odds ratio; $95 \% \mathrm{CI}$ OR $-95 \%$ confidence interval odds ratio

affect the increased risk of developing hypertension. Diagnosis of hypertension was the dependent variable.

Finally, the following set of explanatory variables was used: birth weight, height, weight, WHR, family history of hypertension, presence of obesity among members of the closest family, type II diabetes among members of the closest family, cardiovascular disease among members of the closest family. It was tested to find which variables were useful for the prediction of developing hypertension.

The results of the logistic regression model for risk of hypertension in young adults are shown in Table 2.

The final form of logistic regression model is: $\hat{\pi}=\frac{e^{g(x)}}{1+e^{g(x)}}$ Where $\hat{\mathrm{g}}(\mathrm{x})=-0.097 \times$ height $+0.085 \times$ $\times$ weight $+7.764 \times$ WHR $+1.312 \times$ family hypertension, where "family hypertension" means the presence of hypertension among members of the closest family - father, mother, siblings, grandfather and grandmother -1 if hypertension is present in 1 of the family members, 2 if in 2 of the members etc.

On the basis of a logistic regression model one can estimate the probability of a student developing hypertension.

Testing of the developed algorithm was carried out at a school on students aged 15-17.108 students completed questionnaires by themselves. In all students $\mathrm{BP}$ was measured three times using the oscillometric method. The basic statistics of the control group on which the model was tested are listed in Table 1. Sensitivity and specificity of the developed algorithm was calculated for the estimated risk $>50 \%$ and $>75 \%$ as a positive result of the screening test. Predictive value for positive and negative results was also calculated. The mean of three BP measurements was analyzed. Systolic and/or diastolic BP > 95 percentile according to norms for sex age and height or $>140$ and/or $90 \mathrm{mmHg}$ were considered test confirmation. The results are shown in Figure 2.
For the test group ROC analysis was performed (Fig. 3). In order to demonstrate results better, sensitivity and specificity values for a greater number of thresholds can be seen in Table 3 .

Based on test results obtained, an algorithm was proposed that could be suitable for practical use for detection of hypertension, using the created risk model (Fig. 4).

\section{Discussion}

Conducting epidemiological studies on the prevalence of hypertension in children and adolescents requires a different approach than in adults. This is due to the need of taking into account the specific nature of the developmental age population, in particular development of systems and organs that are involved in the complex process of BP control. Differences and difficulties in conducting screening tests for hypertension in children and adolescents arise from the need of using different cuffs, precisely matching the arm circumference, application of standards appropriate for age, sex, height, use of charts and tables to evaluate other parameters, such as height or BMI. In children one should always take into account possible measurement errors, resulting from physical activity, increased excitability and emotions during measurements taken by a school nurse at her office [44].

All of the differences and difficulties mentioned above result in screening of the studied age group being extremely laborious, difficult to perform and generates huge costs. Screening programs used in the prevention of cardiovascular diseases may take the form of organized programs or are being implemented in an opportunistic form [15, 16, 23].

One cannot forget that according to existing guidelines, BP measurement should be an integral part of any medical visit in every child over 2 years old. It should be performed at least once a year. This recommendation is usually respected in the so-called healthy children clinics during periodic 


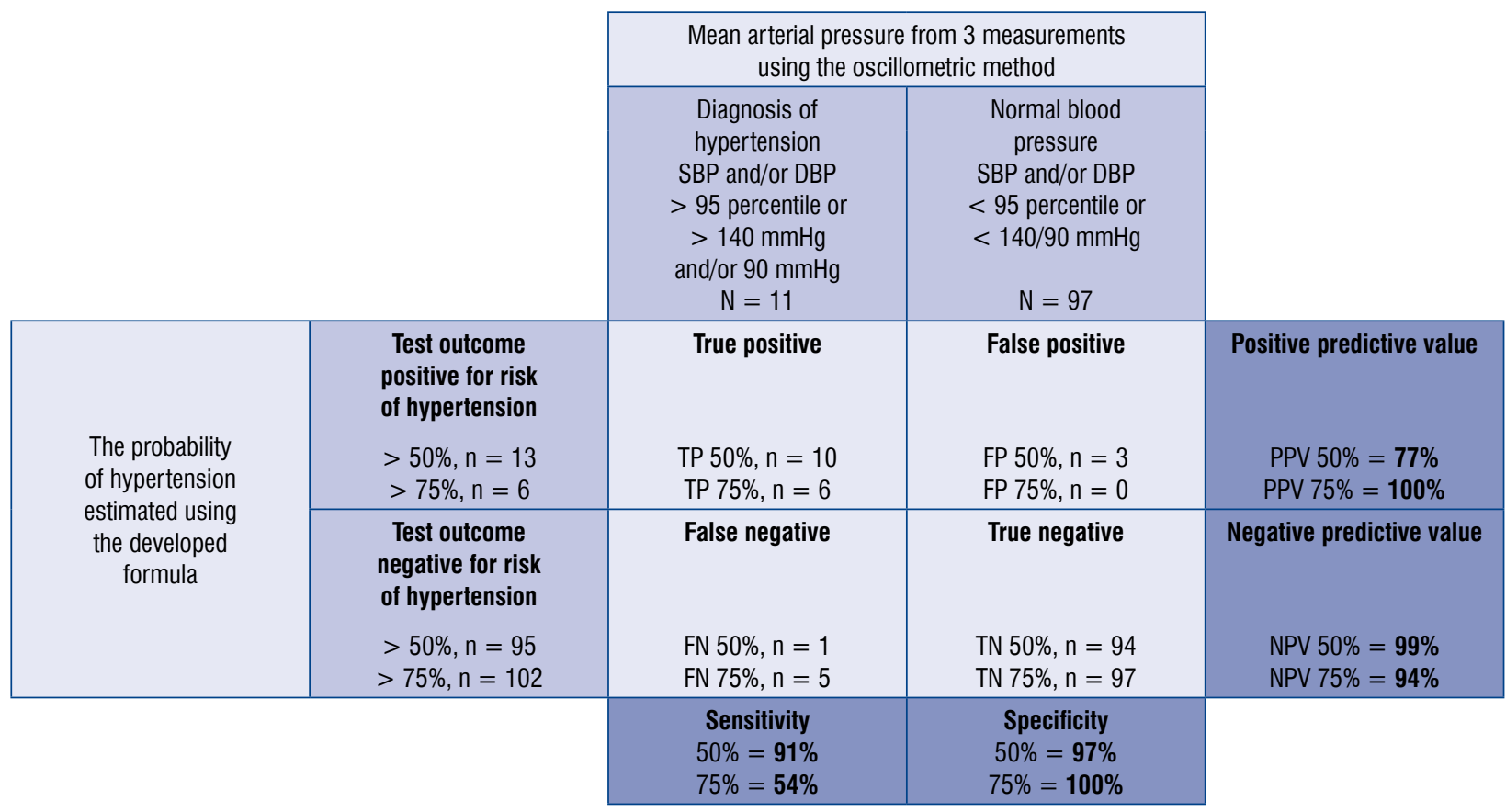

Figure 2. Sensitivity, specificity, positive predictive value, negative predictive value in the tested group; SBP - systolic blood pressure; DBP — diastolic blood pressure; TP — true positive; FP — false positive; FN — false negative; $\mathrm{TN}$ - true negative; PPV — positive predictive value; NPV — negative predictive value.

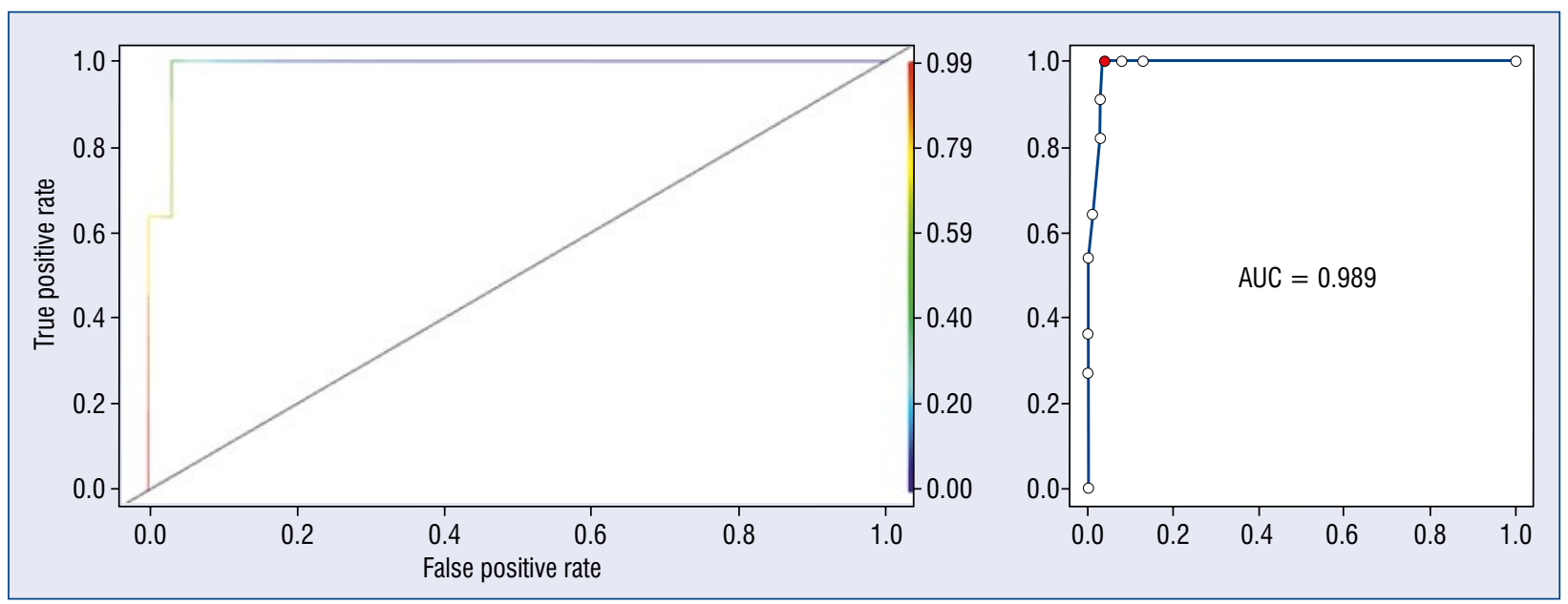

Figure 3. Receiver operating characteristic curve for risk of hypertension calculated using an algorithm. The optimal cut-off point for risk of hypertension, calculated using the algorithm is $46 \%$ area under the curve (AUC): 0.989 (0.973;1.00; cut-off: 0.4597$)$. For this value: sensitivity $=100 \%$; specificity $=97 \%$; positive predictive value $=79 \%$; negative predictive value $=100 \%$.

Table 3. Sensitivity and specificity for different risk thresholds.

\begin{tabular}{lccccccccccc}
\hline Risk thresholds & 0.1 & 0.2 & 0.3 & 0.4 & $\mathbf{0 . 4 6}$ & $\mathbf{0 . 5}$ & $\mathbf{0 . 6}$ & $\mathbf{0 . 7}$ & $\mathbf{0 . 7 5}$ & $\mathbf{0 . 8}$ & $\mathbf{0 . 9}$ \\
\hline Sensitivity & 1 & 1 & 1 & 1 & $\mathbf{1}$ & 0.91 & 0.82 & 0.64 & 0.54 & 0.36 & 0.27 \\
Specificity & 0.87 & 0.92 & 0.96 & 0.96 & $\mathbf{0 . 9 7}$ & 0.97 & 0.97 & 0.99 & 1 & 1 & 1 \\
\hline
\end{tabular}




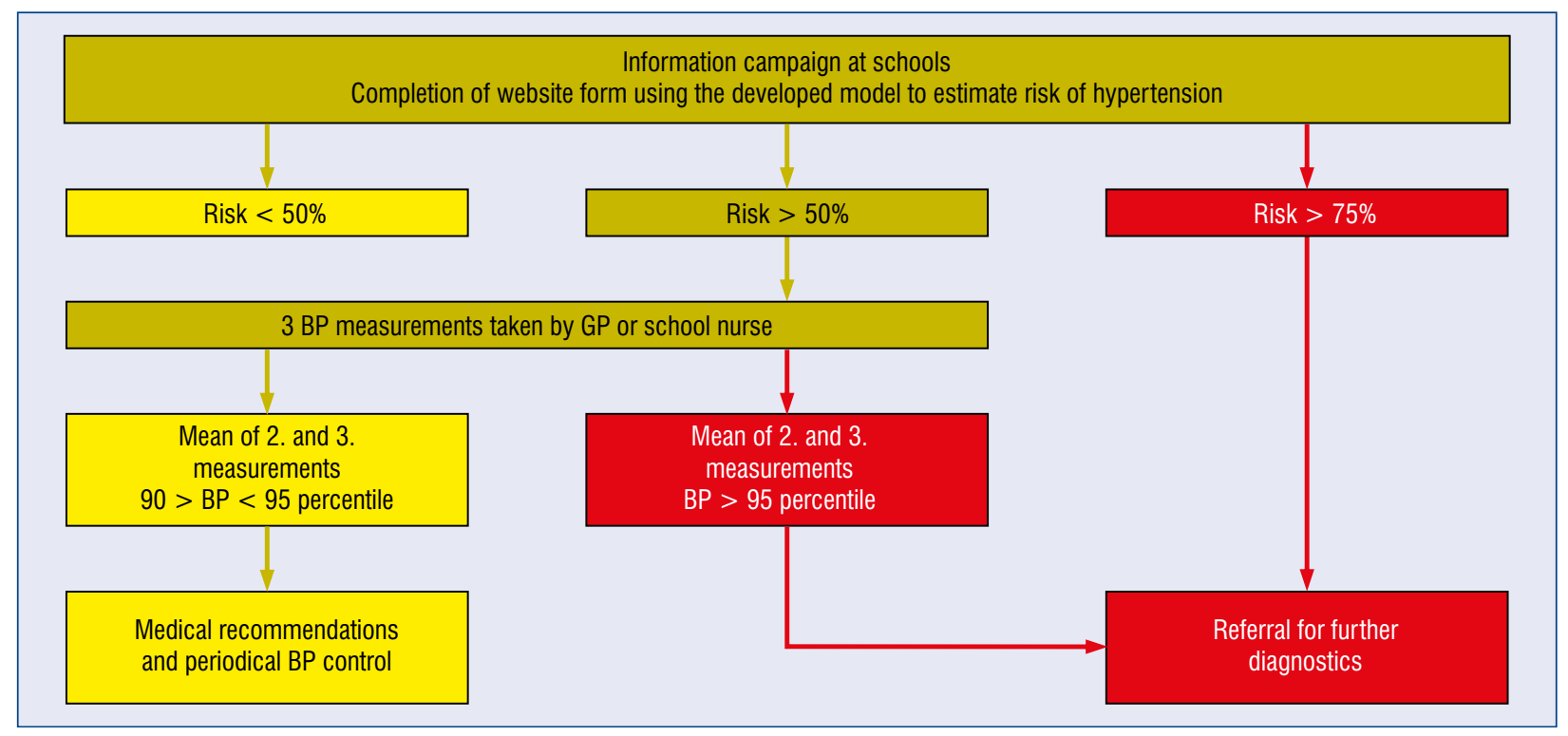

Figure 4. An algorithm to detect hypertension based on a developed model of hypertension probability; BP — blood pressure; GP - general practitioner.

health evaluation and visits and allows for the identification of younger children with hypertension at an early stage, mainly children with secondary forms of hypertension [15, 16, 36, 38, 41].

According to current recommendations, general practitioners are obliged to perform such screening tests, such as: recording history of cardiovascular diseases occurring in the family, taking BP measurements as well as measurements of body weight and height. These screening tests are classified as occasional tests (so-called opportunistic tests). In adolescents they appear to be inefficient and ineffective [36, 38, 41, 44-47].

Teenagers do not seek medical care often, because they are less susceptible to viral diseases of childhood, periodic health evaluations are carried out in schools less often, pupils do not need to undergo mandatory medical examinations in occupational medicine clinics and they suffer less often from chronic diseases than adults do [44-46].

Screening programs are another possibility. These may be smaller, locally funded actions, covering several schools, or larger projects which may for example, be financed by the Ministry of Health, that cover cities and regions. Such programs usually require large amounts of money and an enormous commitment of medical and administrative staff [44-46].

Another model is a screening test based on preselection. It involves screening of patients at risk of studied and a searched for feature - hy- pertension in this case - on the basis of available data, e.g. patient history, medical records or performance of a simple, noninvasive and inexpensive test [44-46].

In order to stratify risk of hypertension, a logistic regression model, describing the risk of hypertension in adolescents between 15 and 17 years of age was invented. A formula was created, allowing for the pre-selection of adolescents at risk of hypertension during the screening of hypertension.

The study needed an easy to use calculator, and one was created that gives the doctor, student or parent an opportunity to assess the risk of hypertension occurrence.

For example, probability of a diagnosis of hypertension for a student weighing $95 \mathrm{~kg}, 177 \mathrm{~cm}$ tall, with WHR $=0.95$, having 2 family members with hypertension is $\sim 70 \%$.

For the same student having 3 family members with hypertension the risk is $\sim 90 \%$.

A student, weighing $75 \mathrm{~kg}, 180 \mathrm{~cm}$ tall and with WHR $=0.85$, with no family history of hypertension has a risk of hypertension $\sim 1 \%$. If this student weighed $110 \mathrm{~kg}$, the risk would increase to about $18 \%$. If there were 1,2 or 3 family members with hypertension, risk would increase to $\sim 45 \%$ and $\sim 75 \%$ and $\sim 95 \%$, respectively.

It turns out that the standard measurement of $\mathrm{BP}$ in children and adolescents is encumbered by a large error. Often, high $\mathrm{BP}$ values recorded during 
the first measurement, become gradually normalized during subsequent measurements.

A large number of false positive results in this group of patients implies that patients are unnecessarily directed to diagnostic expertise, which generates additional costs and exposes the patient to unnecessary stress [14-17, 36].

Conducting screening using the developed algorithm and spreading it with the aid of social media and networking sites frequented by youth, will allow in a short time and without major financial investment or risk of obtaining a large number of false positive results associated with the measurement of BP, to extract a group of young people in which there is a high risk of essential hypertension.

There is no similar, simple algorithm to be found in available literature, that does not require measurement of BP and is useful in screening for hypertension in adolescents [45].

The National High Blood Pressure Education Program's Working Group (NHBPEP) recommended lifestyle interventions (i.e., weight reduction, increased physical activity, and adoption of healthy eating habits) to reduce BP in children and adolescents with prehypertension and hypertension, with pharmacologic approaches reserved for children and adolescents with elevated BP not responding to lifestyle interventions or for those who have secondary causes of hypertension [38]. An updated review conducted by the United States Preventive Services Task Force (USPSTF) in 2012 concluded that even though BP screening in children and adolescents could be effective in identifying high $\mathrm{BP}$, there is still no sufficient evidence on routine screening, and that false positive rates might be high. Public health authorities should work with health-care providers to promote and to improve $\mathrm{BP}$ screening in children and adolescents. For example health-care providers can use healthy children visits and physical examinations of sports participants as opportunities to increase screening rates among children [45]. Still it remains, that routine screening is potentially more effective and less costly than selective screening or no screening [46, 48, 49].

According to the USPSTF guidelines, the primary justification for screening for hypertension in children and adolescents it is that early diagnosis of essential hypertension can lead to interventions in reducing BP in childhood and adolescence, thus reducing the risk of cardiovascular event occurrence and death in adulthood $[44,50]$.
The primary prevention of atherosclerosis should precede its clinical manifestation and begin in early childhood $[48,49]$.

\section{Conclusions}

Body weight, WHR and incidence of hypertension in the family are the strongest predictors of hypertension in teenagers. The proposed screening algorithm can be a useful tool for selecting teenagers at risk of hypertension and in need of specialized diagnostics. There is a plan to upscale research and test the algorithm on larger groups on a larger scale.

\section{Conflict of interest: None declared}

\section{References}

1. Kearney PM, Whelton M, Reynolds K, et al. Global burden of hypertension: analysis of worldwide data. Lancet. 2005; 365(9455): 217-223, doi: 10.1016/S0140-6736(05)17741-1, indexed in Pubmed: 15652604 .

2. Primatesta P, Brookes M, Poulter N. Improved hypertension management and control. Hypertension. 2001; 38(4): 827-832, doi: 10.1161/hyp.38.4.827.

3. Macedo M, Lima M, Silva A, et al. Prevalence, awareness, treatment and control of hypertension in Portugal: the PAP study. J Hypertens. 2005; 23(9): 1661-1666, doi: 10.1097/01. hjh.0000179908.51187.de.

4. Altun B, Arici M, Nergizoğlu G, et al. Prevalence, awareness, treatment and control of hypertension in Turkey (the PatenT study) in 2003. J Hypertensi. 2005; 23(10): 1817-1823, doi: 10.1097/01.hjh.0000176789.89505.59.

5. Ong K, Cheung B, Man Y, et al. Prevalence, awareness, treatment, and control of hypertension among united states adults 1999-2004. Hypertension. 2007; 49(1): 69-75, doi: 10.1161/01. hyp.0000252676.46043.18.

6. Cifkova R, Skodova Z, Lanska V, et al. Trends in blood pressure levels, prevalence, awareness, treatment, and control of hypertension in the Czech population from 1985 to 2000/01. J Hypertens. 2004; 22(8): 1479-1485, doi: 10.1097/01. hjh.0000133737.77866.3e.

7. Whelton PK, Carey RM, Aronow WS, et al. 2017 ACC/AHA/ AAPA/ABC/ACPM/AGS/APhA/ASH/ASPC/NMA/PCNA Guideline for the Prevention, Detection, Evaluation, and Management of High Blood Pressure in Adults: A Report of the American College of Cardiology/American Heart Association Task Force on Clinical Practice Guidelines. Hypertension. 2018; 71(6): e13-e115.

8. Piepoli MF, Hoes AW, Agewall S, et al. 2016 European Guidelines on cardiovascular disease prevention in clinical practice: The Sixth Joint Task Force of the European Society of Cardiology and Other Societies on Cardiovascular Disease Prevention in Clinical Practice (constituted by representatives of 10 societies and by invited experts) Developed with the special contribu- 
tion of the European Association for Cardiovascular Prevention \& Rehabilitation (EACPR). Atherosclerosis. 2016; 252: 207-274.

9. Nadrowski P, Podolecka E, Pajak A, et al. How does the risk of cardiovascular death and cardiovascular risk factor profiles differ between socioeconomic classes in Poland: A country in transition. Cardiol J. 2019; 26(5): 493-502, doi: 10.5603/cj.a2018.0003, indexed in Pubmed: 29570212.

10. Zdrojewski T, Szpakowski P, Bandosz P, et al. Arterial hypertension in Poland in 2002. J Hum Hypertens. 2004; 18(8): 557-562, doi: 10.1038/sj.jhh.1001739, indexed in Pubmed: 15129232.

11. Vasan RS, Beiser A, Seshadri S, et al. Residual lifetime risk for developing hypertension in middle-aged women and men: The Framingham Heart Study. JAMA. 2002; 287(8): 1003-1010, doi: 10.1001/jama.287.8.1003, indexed in Pubmed: 11866648.

12. Staessen J, Fagard R, Thijs L, et al. Randomised double-blind comparison of placebo and active treatment for older patients with isolated systolic hypertension. Lancet. 1997; 350(9080): 757-764, doi: 10.1016/s0140-6736(97)05381-6.

13. Beckett N, Peters R, Fletcher A, et al. Treatment of Hypertension in Patients 80 Years of Age or Older. N Engl J Med. 2008; 358(18): 1887-1898, doi: 10.1056/nejmoa0801369, indexed in Pubmed: 18378519.

14. Ostchega Y, Carroll M, Prineas RJ, et al. Trends of elevated blood pressure among children and adolescents: data from the National Health and Nutrition Examination Survey1988-2006. Am J Hypertens. 2009; 22(1): 59-67, doi: 10.1038/ajh.2008.312, indexed in Pubmed: 19039307.

15. Falkner B, Lurbe E, Schaefer F. High blood pressure in children: clinical and health policy implications. J Clin Hypertens (Greenwich). 2010; 12(4): 261-276, doi: 10.1111/j.17517176.2009.00245.x, indexed in Pubmed: 20433547.

16. Rao G. Diagnosis, epidemiology, and management of hypertension in children. Pediatrics. 2016; 138(2), doi: 10.1542/peds.20153616, indexed in Pubmed: 27405770.

17. Chen L, Simonsen N, Liu Li. Racial differences of pediatric hypertension in relation to birth weight and body size in the united states. PLoS ONE. 2015; 10(7): e0132606, doi: 10.1371/journal. pone. 0132606 .

18. Litwin M, Niemirska A, Obrycki Ł, et al. Zalecenia Sekcji Pediatrycznej Polskiego Towarzystwa Nadciśnienia Tętniczego dotyczące postępowania diagnostycznego i terapeutycznego w nadciśnieniu tętniczym u dzieci i młodzieży. Arterial Hypertension. 2018; 22(2): 45-73, doi: 10.5603/ah.2018.0007.

19. Kulaga Z, Litwin M, Grajda A, et al. Rozkłady wartości ciśnienia krwi w populacji referencyjnej dzieci i młodzieży w wieku szkolnym. Standardy Medyczne Pediatria 2010; 7(5-6. : 853-864.

20. Litwin M, Sladowska J, Antoniewicz J, et al. Metabolic abnormalities, insulin resistance, and metabolic syndrome in children with primary hypertension. Am J Hypertens. 2007; 20(8): 875-882, doi: 10.1016/j.amjhyper.2007.03.005.

21. Litwin M, Niemirska A, Śladowska-Kozlowska J, et al. Regression of target organ damage in children and adolescents with primary hypertension. Pediatric Nephrol. 2010; 25(12): 2489-2499, doi: 10.1007/s00467-010-1626-7.

22. Luepker R, Jacobs D, Prineas R, et al. Secular trends of blood pressure and body size in a multi-ethnic adolescent population: 1986 to 1996. J Pediatr. 1999; 134(6): 668-674, doi: 10.1016/ s0022-3476(99)70279-9.

23. Battistoni A, Canichella F, Pignatelli G, et al. Hypertension in young people: epidemiology, diagnostic assessment and therapeutic approach. High Blood Press Cardiovasc Prev. 2015; 22(4):
381-388, doi: 10.1007/s40292-015-0114-3, indexed in Pubmed: 26153401.

24. Essouma M, Noubiap JJ, Bigna JJ, et al. Hypertension prevalence, incidence and risk factors among children and adolescents in Africa: a systematic review and meta-analysis protocol. BMJ Open. 2015; 5(9): e008472, doi: 10.1136/bmjopen-2015-008472, indexed in Pubmed: 26373403.

25. Zhou Y, Qian Z, Vaughn MG, et al. Epidemiology of elevated blood pressure and associated risk factors in Chinese children: the SNEC study. J Hum Hypertens. 2016; 30(4): 231-236, doi: 10.1038/jhh.2015.104, indexed in Pubmed: 26446390.

26. Akinlua JT, Meakin R, Umar AM, et al. Current prevalence pattern of hypertension in nigeria: a systematic review. PLoS One. 2015; 10(10): e0140021, doi: 10.1371/journal.pone.0140021, indexed in Pubmed: 26461923.

27. Sweeting HN. Measurement and definitions of obesity in childhood and adolescence: a field guide for the uninitiated. Nutr J. 2007; 6: 32, doi: 10.1186/1475-2891-6-32, indexed in Pubmed: 17963490.

28. Kosti RI, Panagiotakos DB. The epidemic of obesity in children and adolescents in the world. Cent Eur J Public Health. 2006; 14(4): 151-159, indexed in Pubmed: 17243492.

29. Kedzior A, Jakubek-Kipa K, Brzuszek M, et al. Trends in prevalence of childhood overweight and obesity on the World, in Europe and in Poland. Endokrynol Ped. 2017; 1(58): 41-48.

30. Kułaga Z, Litwin M, Tkaczyk M, et al. Polish 2010 growth references for school-aged children and adolescents. Eur J Pediatr. 2011; 170(5): 599-609, doi: 10.1007/s00431-010-1329-x, indexed in Pubmed: 20972688.

31. Malecka-Tendera E, Klimek K, Matusik P, et al. Obesity and overweight prevalence in Polish 7- to 9-year-old children. Obes Res. 2005; 13(6): 964-968, doi: 10.1038/oby.2005.112, indexed in Pubmed: 15976137.

32. Ulijaszek SJ, Koziel S. Nutrition transition and dietary energy availability in Eastern Europe after the collapse of communism. Econ Hum Biol. 2007; 5(3): 359-369, doi: 10.1016/j. ehb.2007.08.007, indexed in Pubmed: 17933595.

33. Ostrowska-Nawarycz L, Nawarycz T. Prevalence of excessive body weight and high blood pressure in children and adolescents in the city of Lodz. Kardiol Pol. 2007; 65(9): 1079-1088.

34. Hanevold C, Waller J, Daniels S, et al. The effects of obesity, gender, and ethnic group on left ventricular hypertrophy and geometry in hypertensive children: a collaborative study of the International Pediatric Hypertension Association. Pediatrics. 2004; 113(2): 328-333, doi: 10.1542/peds.113.2.328, indexed in Pubmed: 14754945.

35. Litwin M, Niemirska A, Sladowska J, et al. Left ventricular hypertrophy and arterial wall thickening in children with essential hypertension. Pediatr Nephrol. 2006; 21(6): 811-819, doi: 10.1007/s00467-006-0068-8, indexed in Pubmed: 16565870.

36. Flynn J, Kaelber D, Baker-Smith C, et al. Clinical practice guideline for screening and management of high blood pressure in children and adolescents. Pediatrics. 2017; 140(3): e20171904, doi: 10.1542/peds.2017-1904.

37. Floriańczyk T, Gołąbek-Dylewska M, Kucińska B, et al. Evaluation of left ventricular function in overweight children and teenagers with arterial hypertension and white coat hypertension. Cardiol J. 2019; 26(4): 343-349, doi: 10.5603/cj.a2017.0151, indexed in Pubmed: 29240959.

38. The Fourth Report on the Diagnosis, Evaluation, and Treatment of High Blood Pressure in Children and Adolescents. Pediatrics. 2004; 114(2): 555-576, doi: 10.1542/peds.114.2.s2.555. 
39. Urbina E, Alpert B, Flynn J, et al. Ambulatory blood pressure monitoring in children and adolescents: recommendations for standard assessment: a scientific statement from the American Heart Association Atherosclerosis, Hypertension, and Obesity in Youth Committee of the council on cardiovascular disease in the young and the council for high blood pressure research. Hypertension. 2008; 52(3): 433-451, doi: 10.1161/HYPERTENSIONAHA.108.190329, indexed in Pubmed: 18678786.

40. Wühl E, Witte K, Soergel M, et al. Distribution of 24-h ambulatory blood pressure in children: normalized reference values and role of body dimensions. J Hypertens. 2002; 20(10): 1995-2007, doi: 10.1097/00004872-200210000-00019, indexed in Pubmed: 12359978 .

41. Mancia G, Backer GDe, Dominiczak A, et al. 2007 Guidelines for the Management of Arterial Hypertension. J Hypertens. 2007; 25(6): 1105-1187, doi: 10.1097/hjh.0b013e3281fc975a.

42. Chobanian A, Bakris G, Black H, et al. Seventh report of the joint national committee on prevention, detection, evaluation, and treatment of high blood pressure. Hypertension. 2003; 42(6): 1206-1252, doi: 10.1161/01.hyp.0000107251.49515.c2.

43. Bergman RN, Stefanovski D, Buchanan TA, et al. A better index of body adiposity. Obesity (Silver Spring). 2011; 19(5): 1083-1089, doi: 10.1038/oby.2011.38, indexed in Pubmed: 21372804.

44. Thompson M, Dana T, Bougatsos C, et al. Screening for hypertension in children and adolescents to prevent cardiovascular disease. Pediatrics. 2013; 131(3): 490-525, doi: 10.1542/peds.20123523, indexed in Pubmed: 23439904.
45. Thompson M, Dana T, Bougatsos C, et al. U.S. Preventive Services Task Force Evidence Syntheses, formerly Systematic Evidence Reviews. Screening for Hypertension in Children and Adolescents to Prevent Cardiovascular Disease: Systematic Review for the US Preventive Services Task Force. Rockville (MD): Agency for Healthcare Research and Quality. (US): 2013.

46. Wang YC, Cheung AM, Bibbins-Domingo K, et al. Effectiveness and cost-effectiveness of blood pressure screening in adolescents in the United States. J Pediatr. 2011; 158(2): 257-64.e1, doi: 10.1016/j.jpeds.2010.07.058, indexed in Pubmed: 20850759.

47. Jarosz M, Wolańska D, Stolińska H, et al. Nutrition and lifestyle in patients pharmacologically treated due to hypertension. Cardiol J. 2016; 23(5): 491-496, doi: 10.5603/CJ.a2016.0049, indexed in Pubmed: 27439369.

48. Perng W, Rifas-Shiman SL, Kramer MS, et al. Early weight gain, linear growth, and mid-childhood blood pressure: a prospective study in project viva. Hypertension. 2016; 67(2): 301-308, doi: 10.1161/HYPERTENSIONAHA.115.06635, indexed in Pubmed: 26644238.

49. So HK, Yip GK, Choi KC, et al. Association between waist circumference and childhood-masked hypertension: A communitybased study. J Paediatr Child Health. 2016; 52(4): 385-390, doi: 10.1111/jpc.13121.

50. Hamoen M, de Kroon MLA, Welten M, et al. Childhood prediction models for hypertension later in life: a systematic review. J Hypertens. 2019; 37(5): 865-877, doi: 10.1097/ HJH.0000000000001970, indexed in Pubmed: 30362985. 